\title{
The challenges of adherence to infant feeding choices in prevention of mother-to-child transmission of HIV infections in South East Nigeria
}

This article was published in the following Dove Press journal:

Patient Preference and Adherence

26 March 2014

Number of times this article has been viewed

Lucky O Lawani'

Azubuike K Onyebuchi ${ }^{2}$

Chukwuemeka A lyoke

Robinson C Onoh ${ }^{2}$

Peter O Nkwo ${ }^{3}$

'School of Postgraduate Studies, Department of Community Medicine, University of Nigeria, Enugu Campus, Enugu State, Nigeria; ${ }^{2}$ Department of Obstetrics and Gynaecology, Federal Teaching Hospital, Abakaliki, Ebonyi State, Nigeria; ${ }^{3}$ Department of Obstetrics and Gynaecology, University of Nigeria Teaching Hospital, Enugu, Enugu State, Nigeria
Correspondence: Lucky O Lawani School of Postgraduate Studies, Department of Community Medicine, University of Nigeria, Enugu Campus, Enugu State, 40000I, Nigeria

Tel +234803669 |209

Email lawkins2000@yahoo.com
Background: Global and national efforts in the 21st century are directed toward the elimination of new pediatric HIV infections through evidence-based infant feeding interventions for the prevention of mother-to-child-transmission, with patient preference, motivation, and adherence identified as key factors for success.

Objectives: This study assessed the challenges faced by HIV-infected parturients in adhering to the national infant feeding recommendations and their infant feeding preference for prevention of mother-to-child transmission in South East Nigeria.

Methods: This is a cross-sectional, descriptive, questionnaire-based study of 556 parturients infected with HIV/AIDS.

Results: The mean age of the participants was $28.0 \pm 5.3$ years. The infant feeding choices were made jointly by both partners $(61.1 \%)$ in the antepartum period. The HIV status disclosure rate was $89.2 \%$. A large proportion $(91.7 \%)$ practiced exclusive breastfeeding with highly active antiretroviral therapy, and $7.6 \%$ practiced mixed feeding because of nonadherence to their choice and national/international recommendations on infant feeding in the context of HIV/AIDS. This was mainly a result of pressure from family members $(42.8 \%)$ and cultural practices $(28.5 \%)$. Multivariate logistic regression analysis indicates that adherence was strongly associated with age, marital status, and employment status, but not with residence, educational status, or parity.

Conclusion: Exclusive breastfeeding is predominately the infant feeding choice among HIV-infected parturients in South East Nigeria, but there is still a gap between infant feeding preference and adherence to standard practice as a result of sociocultural challenges associated with risk for mixed feeding and the risk for mother-to-child-transmission of HIV by nursing mothers.

Keywords: PMTCT, HIV, infant feeding, challenges, HAART, adherence

\section{Introduction}

Transmission of HIV in children has become a critical health problem that threatens to undermine the positive effect of child survival strategies in the African continent. Motherto-child transmission (MTCT) is the primary cause of pediatric HIV infections worldwide, accounting for more than $90 \%$ of cases in the absence of prevention of MTCT (PMTCT) interventions. ${ }^{1-3}$ Between 129,000 and 194,000 of the 430,000 pediatric HIV infections worldwide are attributable to breastfeeding without antiretrovirals (ARVs). ${ }^{1,4}$

Nonadherence to recommended infant feeding practices has been known to present great challenges in PMTCT of HIV in children and in achieving the global elimination of new infections by 2015, making international guidelines on infant feeding methods that reduce the risk for HIV transmission and discourage mixed feeding relevant. ${ }^{5,6}$ Breastfeeding has been widely endorsed as an optimal strategy for feeding newborn and young infants, as well as improving child survival (HIV-free survival) 
and achieving Millennium Development Goals 4 and 6 in resource-poor settings. ${ }^{1,3,7}$ Adherence to exclusive breastfeeding $(\mathrm{EBF})$ in the first 6 months of infancy is associated with huge health benefits for children in areas where infant mortality is high, as in most low-income countries of the world. $^{1-3}$ Nigeria adopted the World Health Organization recommendation of EBF as a national infant-feeding strategy. This also has a provision for those who decline, allowing them to exclusively formula feed (EFF) as long as they can fulfill and adhere to AFASS (acceptability, feasibility, affordability, sustainability, and safety). ${ }^{2,3}$ EFF with strict adherence to AFASS may not be feasible in most African settings because of the predominant culture of breastfeeding, harmful cultural practices, lack of safe drinking water, poverty, nondisclosure, family and peer pressure, illiteracy, and ignorance. ${ }^{2,3}$ The inability to fulfill and adhere to AFASS often leads to mixed feeding, which predisposes the infant to malnutrition, diarrhea, pneumonia, malaria, and measles, which are among the most common causes of under-5-years death in most developing countries and have been identified as one of the numerous causes of the setbacks so far recorded in efforts to achieve HIV-free survival for children. ${ }^{2,3}$

There have been reports of some mothers initiating mixedfeeding practices as early as the first month, on the grounds that they were pressured by the family or peers to mix food sources. ${ }^{8}$ Considering the magnitude of this problem, this study was designed to assess the challenges faced by parturients in practicing and adhering to their infant feeding choice and national/international recommendations for PMTCT, as well as to assess the challenges of breastfeeding as a rational and viable option for HIV-free survival of HIV-exposed infants, so as to make recommendations that will address such challenges in our efforts to curb new pediatric HIV infection in South East Nigeria and other similar settings.

\section{Materials and methods}

This was a cross-sectional, descriptive, questionnaire-based study conducted over the course of 1 year (August 1, 2012-July 31, 2013) in four major health care facilities (Federal Teaching Hospital; Mile Four Clinic; General Hospital, Onueke, Abakaliki, Ebonyi state; and Catholic Maternity Hospital in Ogoja) offering PMTCT services to women infected with HIV/AIDS in South East Nigeria. Ethical clearance was obtained from the ethics and research committees of the four health care institutions. All parturients who were HIV-infected and who attended the PMTCT/pediatric clinics for a final polymerase chain reaction test (PCR) when their baby was 18 months old, and who gave consent to be part of the research project, were recruited for the study.
An interviewer-administered, pretested semistructure questionnaire was used to obtain information on the sociodemographic characteristics of the participants, as well as the challenges faced by parturients in adhering to their infant feeding preference and the Nigerian national infant feeding recommendations for PMTCT of HIV. Thereafter, further focused individual and group interviews were then conducted in those who had difficulty adhering to their preference to determine the factors responsible for nonadherence and also to counsel them on how to overcome these challenges with the help of adherence counselors and peer/psychosocial support groups. A total of 556 women participated in the study, and all the questionnaires were suitable for analysis. The data were analyzed with Epi Info ${ }^{\mathrm{TM}}$, version 7 (Centers for Disease Control and Prevention, Atlanta, GA, USA). The process involved the determination of mean, simple percentages; multivariate logistic regression analysis was used to examine the relationship between adherence and patient's characteristics. Confidence interval was set at $95 \%$, with levels $<0.05$ considered statistically significant.

\section{Results}

The mean age of the participants in this study was $28.0 \pm 5.3$ years, indicating a predominately young population within the reproductive age bracket. The majority (96.5\%) of these women were in stable marital relationships, which is important, considering the significant role of male/ partner involvement in adhering to PMTCT interventions, especially in making an informed infant feeding choice in the African setting. Table 1 indicates the sociodemographic characteristics of the participants.

A multivariate logistic regression analysis that examined the relationship between adherence and patient characteristics indicates that adherence was strongly associated with age, marital status, and employment status, but not with residence, educational status, or parity. Relative to age, adherence was greater in the subset of participants who were 36-40 years old (odds ratio [OR], 1.10; 95\% confidence interval [CI], $1.00-1.20)$ and least in the subset of those who were 21-25 years old (OR, 1.21; 95\% CI, 1.00-1.31). It was higher among married parturients (OR, 1.34; 95\% CI, 1.13-1.52) and lowest among single parturients (OR, 0.90; 95\% CI, 1.00-1.30). Adherence was also higher in the unemployed (OR, 2.10; 95\% CI, 1.20-2.45) and lower in the employed (OR, 0.78; 95\% CI, 0.68-0.90). All participants in this study had booked for antenatal care and had their care supervised by skilled birth attendants in the last confinement. They also received counseling on infant feeding and adherence during health talks/education given during every antenatal care visit 
Table I Sociodemographic characteristics of participants, $\mathrm{N}=556$

\begin{tabular}{|c|c|}
\hline Variables & n (\%) \\
\hline \multicolumn{2}{|l|}{ Age, years } \\
\hline$<20$ & $\mathrm{I}(0.2)$ \\
\hline $21-25$ & I 34 (24.I) \\
\hline $26-30$ & $201(36.2)$ \\
\hline $3 I-35$ & $182(32.7)$ \\
\hline $36-40$ & $38(6.8)$ \\
\hline \multicolumn{2}{|l|}{ Marital status } \\
\hline Married & $536(96.4)$ \\
\hline Single & $16(2.9)$ \\
\hline Separated & $3(0.5)$ \\
\hline Divorced & I $(0.2)$ \\
\hline \multicolumn{2}{|c|}{ Educational status } \\
\hline None & $45(8.1)$ \\
\hline Primary & $203(36.5)$ \\
\hline Secondary & $285(5 \mid .3)$ \\
\hline Tertiary & $23(4.1)$ \\
\hline \multicolumn{2}{|c|}{ Employment status } \\
\hline Employed & 398 (7I.6) \\
\hline Unemployed & I 58 (28.4) \\
\hline \multicolumn{2}{|l|}{ Residence } \\
\hline Urban & I5I (27.2) \\
\hline Rural & 405 (72.8) \\
\hline \multicolumn{2}{|l|}{ Parity } \\
\hline 1 & 140 (25.2) \\
\hline $2-4$ & $4 \mid 4(74.4)$ \\
\hline$\geq 5$ & $2(0.4)$ \\
\hline
\end{tabular}

and subsequently. It was therefore not surprising that $91.7 \%$ opted for EBF, which is the focus of the World Health Organization and the Nigerian national infant feeding recommendations by the Federal Ministry of Health (FMOH). However, $7.6 \%$ of the mothers still practiced mixed feeding despite receiving education and adherence counseling on its harmful effects and its risk implications in MTCT of HIV. Table 2 shows that all the mothers who practiced EBF made an informed infant feeding choice antepartum. This was made jointly by the partners in $61.1 \%$ of cases, indicating some level of male involvement/participation in PMTCT interventions, which is the recommended standard of care, especially in enhancing adherence to infant feeding choice and other PMTCT interventions. In contrast, more than a third $(37.6 \%)$ of the mothers made the choice alone.

Considering that nondisclosure could be a reason for nonadherence and mixed feeding, disclosure status was ascertained. It was found that $89.2 \%$ of the participants had disclosed their status, whereas $10.8 \%$ had not. This and other factors may have accounted for the proportion that still practiced mixed feeding. Those who practiced mixed feeding, against the recommended feeding option of EBF or EFF in combination with ARVs with fulfillment and adherence to AFASS, did so on account of sociocultural and other challenges that prompted
Table 2 Infant feeding practice (within 6 months of life), time of decision, disclosure of status, and reasons for mixed feeding

\begin{tabular}{|c|c|}
\hline Variables & n (\%) \\
\hline \multicolumn{2}{|l|}{ Infant feeding practice, $\mathrm{N}=556$} \\
\hline Exclusive breastfeeding & $510(91.7)$ \\
\hline Exclusive formula feeding & $4(0.7)$ \\
\hline Mixed feeding & $42(7.6)$ \\
\hline \multicolumn{2}{|l|}{ Time of decision, $\mathrm{N}=556$} \\
\hline Antepartum & $556(100.0)$ \\
\hline Intrapartum & $0(0.0)$ \\
\hline Postpartum & $0(0.0)$ \\
\hline \multicolumn{2}{|l|}{ Who made choice, $\mathrm{N}=556$} \\
\hline Parturient (woman) only & $209(37.6)$ \\
\hline Partner (husband) only & $7(1.3)$ \\
\hline Jointly & $340(6 I . I)$ \\
\hline \multicolumn{2}{|l|}{ Disclosure of status, $\mathrm{N}=556$} \\
\hline Yes & $496(89.2)$ \\
\hline No & $60(10.8)$ \\
\hline \multicolumn{2}{|l|}{ Reasons for mixed feeding, $\mathrm{N}=42$} \\
\hline Pressure from family members & $18(42.8)$ \\
\hline Cultural practices & $12(28.5)$ \\
\hline Nondisclosure & $4(9.5)$ \\
\hline Peer pressure & $2(4.8)$ \\
\hline Ignorance of the risk & $2(4.8)$ \\
\hline Inability to meet AFASS for EFF & I (2.4) \\
\hline Breast problems & I (2.4) \\
\hline Job commitment & I (2.4) \\
\hline Maternal medical conditions & I (2.4) \\
\hline \multicolumn{2}{|l|}{ Duration of breastfeeding, $N=552$} \\
\hline$<$ I year & $107(19.4)$ \\
\hline I year & $445(80.6)$ \\
\hline$>$ I year & $0(0.0)$ \\
\hline
\end{tabular}

Abbreviations: AFASS, acceptable feasible affordable sustainable and safe; EFF, exclusive formula feeding.

nonadherence, as shown in Table 2, where pressure from family members $(42.8 \%)$ and cultural practices $(28.5 \%)$ led to administration of water and herbal medications. Most (80.6\%) of the women breastfeed for at least 1 year, as recommended by the FMOH. All mothers were receiving highly active ARV therapy, with $69.6 \%$ receiving it for prophylaxis and $30.4 \%$ for treatment, mainly during the antepartum, intrapartum, and breastfeeding periods, as depicted in Table 3. All HIV-exposed babies received nevirapine syrup prophylaxis for at least 6 weeks, as shown in Table 4.

\section{Discussion}

Breastfeeding with ARVs reduces risk for HIV transmission and improves child survival of the common causes of under5-years deaths in sub-Saharan Africa, whereas formula feeding carries zero risk for transmission but is associated with increased risk for under-5-years mortality. ${ }^{3,9}$ Globally, the weight of current evidence favors EBF for 6 months with ARVs to prevent MTCT through breast milk, especially in low-income countries such as Nigeria., ${ }^{2,9}$ Despite this evidence, some proportion 
Table 3 Maternal highly active antiretroviral therapy, indication and period on highly active antiretroviral therapy, $\mathrm{N}=556$

\begin{tabular}{ll}
\hline Variables & $\mathbf{n}(\%)$ \\
\hline Received highly active antiretroviral therapy & \\
$\quad$ Yes & $556(100.0)$ \\
No & $0(0.0)$ \\
Indication & \\
$\quad \begin{array}{l}\text { Prophylaxis } \\
\quad \text { Treatment }\end{array}$ & $387(69.6)$ \\
Period & $169(30.4)$ \\
$\quad \begin{array}{l}\text { Antepartum and intrapartum only } \\
\text { Antepartum, intrapartum, and postpartum } \\
\text { (during breastfeeding) }\end{array}$ & $4(0.7)$ \\
Continued after breastfeeding & $383(68.9)$ \\
\hline
\end{tabular}

of parturients still practice mixed feeding, which exposes infants to the risk of being infected with HIV and also predisposes them to diarrhea and other common causes of under5-years deaths, making efforts to achieve an HIV-free survival almost a mirage. In this study, the majority $(91.7 \%)$ of the participants practiced and adhered to the recommendations by the World Health Organization and the Nigerian FMOH that support EBF in the first 6 months of life with ARVs; the implication of this is a positive step toward achieving an HIV-free infant survival in this region, but this finding is at variance with reports from Malawi, where only $20 \%$ of HIV-infected parturients practiced and adhered to EBF. ${ }^{10}$

Sociocultural characteristics such as employment and educational status have been shown by researchers to influence the infant feeding practice and adherence to standards, as noted in this study, where job commitment was identified as the cause of nonadherence, resulting in mixed feeding, in $2.6 \%$ of the respondents. This is similar to the findings in Northwest Ethiopia. ${ }^{1,11}$ Most (96.5\%) of participants in this study were in stable marital relationships with partner involvement, which has been identified as a plus in adhering to the chosen infant feeding option. ${ }^{1}$ Male/partner involvement in PMTCT interventions has been shown by previous studies to play a significant role in adherence to the infant feeding recommendation of EBF, thus reducing

Table 4 Newborn nevirapine prophylaxis and duration, $\mathrm{N}=556$

\begin{tabular}{ll}
\hline Variables & $\mathbf{n ~ ( \% )}$ \\
\hline $\begin{array}{l}\text { Received nevirapine } \\
\quad \text { Yes }\end{array}$ & $556(100.0)$ \\
$\quad$ No & $0(0.0)$ \\
Duration & \\
$\quad<6$ weeks & $0(0.0)$ \\
6 weeks only & $556(100.0)$ \\
$>6$ weeks & $0(0.0)$ \\
\hline
\end{tabular}

the chances of mixed feeding. ${ }^{1,2}$ Partner disclosure and male/partner involvement could be an important step in the Nigerian setting (South East Nigeria) in preventing mixed feeding, which may result from pressure from mothers-inlaw, family members, and peers, who often assist in rearing the newborn, as part of the African cultural practice in the extended family system. ${ }^{1}$ Most of these in-laws sometimes insist on giving water and herbal medications (mixed feeding) to improve perinatal survival against the wish of women, who often times have no say in issues concerning their health and that of their babies, except when there are interventions by the male partners, whose opinions are often considered superior and are respected by family members and peers.

Studies have also demonstrated that mothers-in-law see themselves as responsible for family health issues and child care in the postpartum period and beyond. ${ }^{12}$ They sometimes expect their daughters-in-law to breastfeed in a customary manner, and generally have a negative disposition toward the infant feeding preference of the parturients. ${ }^{12}$ Mixed feeding was noted to be more common among women who had not disclosed their HIV-positive status and among women who had limited understanding of MTCT of HIV. ${ }^{8}$ The disclosure rate of $89.2 \%$ recorded in this study may have accounted for the level of adherence to EBF recorded. This finding is similar to and supported by the findings of other researchers, in which breastfeeding was scientifically shown to be a viable option for achievement of an HIV-free survival for all HIV-exposed infants. ${ }^{9}$ The finding that most males were involved in the infant feeding decision-making process (jointly in $61.1 \%$ of cases and singly in $1.3 \%$ in of cases) is also similar to the reports of other researchers. ${ }^{8}$ This may have been responsible for the level of adherence recorded in this study, despite pressure from family members and peers to mix feed. The finding that early informed infant feeding choices were made by all parturients antepartum makes adherence to the option of either EBF or EFF feasible and may have reduced the incidence of mixed feeding in this study. However, this is at variance with reports from South Africa. ${ }^{13}$ Because the Nigerian FMOH and the World Health Organization recommended EBF with ARVs as the infant feeding recommendation for the infants of all HIVpositive parturients as part of PMTCT interventions that have been found to reduce the risk for MTCT of HIV to less than $2 \%,{ }^{2,3,14,15}$ all the participants in this study received highly active ARV therapy for either prophylaxis or treatment, and all the exposed babies received syrup nevirapine for 6 weeks. 
The challenges faced by the participants in adhering to their infant feeding choice (EBF or EFF), which resulted in mixed feeding in this study, were mainly pressure from family members (42.8\%) and cultural practices (28.5\%), whereas others were the inability to fulfill and adhere to AFASS for EFF; peer pressure, nondisclosure, job commitment, maternal medical conditions, and ignorance of the risk for mixed feeding. These sociocultural factors must always be assessed and addressed for each parturient, depending on their needs, before making a choice to avoid the pitfall of nonadherence that often results in mixed feeding. Although this work was able to identify the challenges faced by parturients in adhering to EBF as a viable option for PMTCT of HIV and improving child survival in sub-Saharan Africa, further research is needed to assess the outcome in parturients who practice this national infant feeding recommendation in our setting.

There is still a gap between infant feeding preference and adherence to choice and standard recommendations in the context or setting in which family members and peers are part of the decision-making process with regard to infant feeding methods. Sociocultural challenges are encountered in making and adhering to the infant feeding choice that are often difficult to execute, whether the choice is EBF or replacement feeding. These challenges are associated with nonadherence and the risk of mixed feeding and could increase the risk for new pediatric HIV infections and the number of under5 -years deaths. Strict adherence to an infant feeding option that will ensure HIV-free survival is encouraged for the achievement of Millennium Development Goals 4 and 6 in South East Nigeria.

\section{Acknowledgments}

The authors extend their gratitude to all participants for dedicating their time for the interviews in this study. They are also indebted to the staff of the participating health facilities for their excellent cooperation and support during the data collection process.

\section{Disclosure}

The authors report no conflicts of interest in this work.

\section{References}

1. Muluye D, Woldeyohannes D, Gizachew M, Tiruneh M. Infant feeding practice and associated factors of HIV positive mothers attending prevention of mother to child transmission and antiretroviral therapy clinics in Gondar Town health institutions, Northwest Ethiopia. BMC Public Health. 2012;12:240.

2. Federal Ministry of Health, Nigeria. National Guidelines for the Prevention of Mother-to-Child Transmission of HIV (PMTCT). Available from: http://www.emtct.iatt.org/wp-content/uploads/2013/. Accessed January 16, 2014.

3. UNICEF. HIV and Infant Feeding. 2012. Available from: http://www. unicef.org/nutrition/index_24827.html. Accessed November 13, 2013.

4. Young SL, Mbuya MN, Chantry CJ, et al. Current knowledge and future research on infant feeding in the context of HIV: basic, clinical, behavioral, and programmatic perspectives. Adv Nutr. 2011;2(3): 225-243.

5. UNAIDS 2012 Global Report. UNAIDS World AIDS Day Report. Available from: http://www.un.org/en/events/aidsday/2010/pdf/JC. Accessed November 15, 2013

6. Leshabari SC, Blystad A, Moland KM. Difficult choices: infant feeding experiences of HIV-positive mothers in northern Tanzania. SAHARA J. 2007;4(1):544-555.

7. Ijumba P, Doherty T, Jackson D, Tomlinson M, Sanders D, Persson LÅ. Social circumstances that drive early introduction of formula milk: an exploratory qualitative study in a peri-urban South African community. Matern Child Nutr. 2014;10(1):102-111.

8. Madiba S, Letsoalo R. HIV disclosure to partners and family among women enrolled in prevention of mother to child transmission of HIV program: implications for infant feeding in poor resourced communities in South Africa. Glob J Health Sci. 2013;5(4):1-13.

9. Coovadia H, Kindra G. Breastfeeding to prevent HIV transmission in infants: balancing pros and cons. Curr Opin Infect Dis. 2008;21(1):11-15.

10. Bedell RA, van Lettow M, Landes M. Women's choices regarding HIV testing, disclosure and partner involvement in infant feeding and care in a rural district of Malawi with high HIV prevalence. AIDS Care. 2014;26(4):483-486.

11. Brown BJ, Oladokun RE, Osinusi K. Situation analysis of the existing infant feeding pattern at the commencement of the prevention of mother to child transmission (PMTCT) of HIV programme in Ibadan. Niger J Clin Pract. 2009;12(4):421-428.

12. Falnes EF, Moland KM, Tylleskär T, de Paoli MM, Leshabari SC, Engebretsen IM. The potential role of mother-in-law in prevention of mother-to-child transmission of HIV: a mixed methods study from the Kilimanjaro region, northern Tanzania. BMC Public Health. 2011;11:551.

13. Swarts S, Kruger HS, Dolman RC. Factors affecting mothers' choice of breastfeeding vs formula feeding in the lower Umfolozi district war memorial, KwaZulu-Natal. J Interdisciplinary Health Sci. 2010;15(1):1-8.

14. World Health Organization. Guideline on HIV and infant feeding. Available from: http://whgliddoc.who.int/publications/2010/97892415 Accessed November 15, 2013.

15. World Health Organization. HIV and Infant Feeding Guideline for Decision Makers. Available from: http:/www.unfpaorg/upload/ lib_pub_file/340_filenar. Accessed November 15, 2013.
Patient Preference and Adherence

\section{Publish your work in this journal}

Patient Preference and Adherence is an international, peer-reviewed, open access journal that focusing on the growing importance of patient preference and adherence throughout the therapeutic continuum. Patient satisfaction, acceptability, quality of life, compliance, persistence and their role in developing new therapeutic modalities and compounds to optimize

\section{Dovepress}

clinical outcomes for existing disease states are major areas of interest for the journal. This journal has been accepted for indexing on PubMed Central. The manuscript management system is completely online and includes a very quick and fair peer-review system, which is all easy to use. Visit http://www. dovepress.com/testimonials.php to read real quotes from published authors. 